about $8 \%$ for the natural snow and around $10 \%$ for the resultant compacted column.

Results of mechanical test are shown in Figure 1 with dry snow as a reference (Mellor, 1975). Fracture strength increases with decreasing water content. Observed strength of all is less than one half of the dry snow strength. Measured tensile strength is shown in Figure 2. For the snow columns immediately after extrusion, tensile strength decreases with increasing water content. For the stored samples, frozen snow columns show similar strength to the homogeneous dry specimens, and columns stored at $0^{\circ} \mathrm{C}$ show rather smaller values than frozen ones.

Compacted-snow columns are weak immediately after compression before snow grains have time to bond. Storing the snow columns at $0^{\circ} \mathrm{C}$ may increase their strength. Mechanical tests indicate that stored columns can be used as building materials (e.g. in snow festivals) or for storage of snow.

\section{ACKNOWLEDGEMENTS}

We are grateful to Dr Tadayuki Ohnuma and Professor Katutoshi Tushima, Dr Tsutomu Nakamura and Dr Toshiich Kobayashi for much advice during the test. Thanks are also due to Professor Shunichi Kobayashi and Dr Kaoru Izumi for the use of their cold room and compressive-test machine.

\section{REFERENCE}

Mellor, M. 1975. A review of basic snow mechanics. International Association of Hydrological Sciences Publication 114 (Symposium at Grindelwald 1974 - Snow Mechanics), 251-291.

The accuracy of references in this list and in the text are the responsibility of the authors, to whom queries should be addressed.

\title{
Geomorphological features and distribution of avalanche furrows in heavy snow regions in Japan
}

\author{
Tatsuo Sekiguchi, Masanori Sugiyama and Tadao Hoya \\ Geographical Survey Institute, Ministry of Construction, Kitasato-1, Tsukuba, Ibaraki, 305 Japan
}

\section{SUMMARY}

Slopes where full-depth avalanches often occur have characteristic features which have not been described in detail. We define an "avalanche furrow" as a steep convergent furrow which on aerial photographs looks like a pattern scratched by a needle. We have researched morphological features of avalanche furrows and relationships between avalanches and avalanche furrows using photo interpretation and field survey of study areas in Hokuriku district, central Japan, and the distribution of avalanche furrows based on interpretation of $1: 15000$ scale photos in the whole of Japan.

Avalanche furrows usually appear in groups of two to four. Each is composed of smoothly dissected rock.

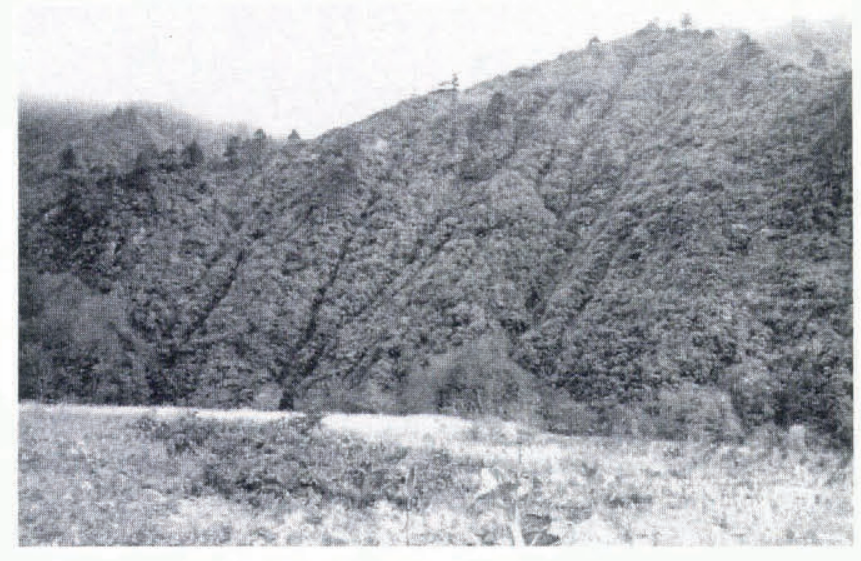

Fig. 1. Terrestrial photograph of "avalanche furrow".
Usually semicircular or U-shaped in section, they are 3$6 \mathrm{~m}$ wide and $2-3 \mathrm{~m}$ deep, and slightly concave in longitudinal section. Lengths range from several tens to several $100 \mathrm{~m}$, and continue from near the ridge line to valley floor (Fig. 1).

Avalanche furrows appear on $76.8 \%$ of slopes where avalanches have occurred. Inversely, traces of avalanches appear in $90.2 \%$ of avalanche furrows. Distribution of inclination of avalanche furrows is centered at $35^{\circ}-50^{\circ}$, while that of non-avalanche furrows where avalanches occurred is concentrated from $30^{\circ}$ to $45^{\circ}$. Avalanche furrows are distributed in heavy snow regions of Japan, especially densely in Hokuriku district and the southern part of Tohoku district. They are good indicators of slopes where avalanches will easily occur.

"Avalanche chutes" (Shimokawa, 1980) appear in slopes where avalanches occur, formed by avalanches and distributed centrally in areas where avalanche furrows appear. We have not investigated their genesis, but we concluded from their distribution that they too are formed by avalanching snow.

\section{REFERENCE}

Shimokawa, K. 1980. Geomorphic study of avalanche chute in the upper drainage basin of the Tadami River. Geographical Review of Japan, 53(3), 171-188.

The accuracy of references in the text and in this list is the responsibility of the authors, to whom queries should be addressed. 